\title{
Una nueva aportación al catálogo del pintor Vicente Alanís
}

\author{
Álvaro Cabezas García \\ Grupo de investigación Laraña, Universidad de Sevilla \\ alvarocabezasgarcia@gmail.com
}

Recientemente pude estudiar con detenimiento la pintura que remata el retablo de ánimas ubicado en la nave del Evangelio de la iglesia de San Juan de la Palma de Sevilla. Se trata de una pieza de mediano tamaño, ejecutada con la técnica del óleo sobre lienzo, que presenta actualmente un estado de conservación muy deficiente -en la fotografía pueden apreciarse tres roturas en la tela, siendo una de ellas de considerables proporciones-, y que representa a San Lorenzo Mártir con sus atributos característicos [1]. Por las amplias similitudes que presenta su forma considero justificado incluirla en el catálogo pictórico de Vicente Alanís Espinosa (Sevilla, 1730-1807). A este autor he dedicado parte de mis estudios (Cabezas, 2011a; Cabezas, 2011b y Cabezas, 2015: 361-371), pero, como es habitual en tantos artistas, la investigación científica sigue ofreciendo caminos de exploración que hacen posible proponer nuevas aportaciones a la nómina de las pinturas ya conocidas.

El santo aparece representado según el modelo que Francisco de Zurbarán (Fuente de Cantos, 1598-Madrid, 1664), realizó en 1636 para el convento de San José de Sevilla y que, tras los sucesos de la Guerra de Independencia, viajó por Europa hasta acabar expuesto en el Museo del Hermitage de San Petersburgo. La obra del pintor extremeño debió resultar referencial para los artistas de siglos posteriores, ya que, según recientes descubrimientos, José María Arango (Sevilla, 1790-1833), se sirvió de ella para componer su propia versión (Valdivieso, 1986 [2002]: 369). La composición es sencilla: la figura del mártir aparece ocupando casi todo el espacio, de pie y calzado, como exponiéndose a la contemplación del fiel. Viste un alba blanca con encaje en los puños y en los bajos y sobre ella lleva una dalmática de color rojo con mangas abiertas. Una cenefa dorada recorre los bordes y tiene correspondencia con otra que traza un rectángulo en el interior de la prenda, estando adornado

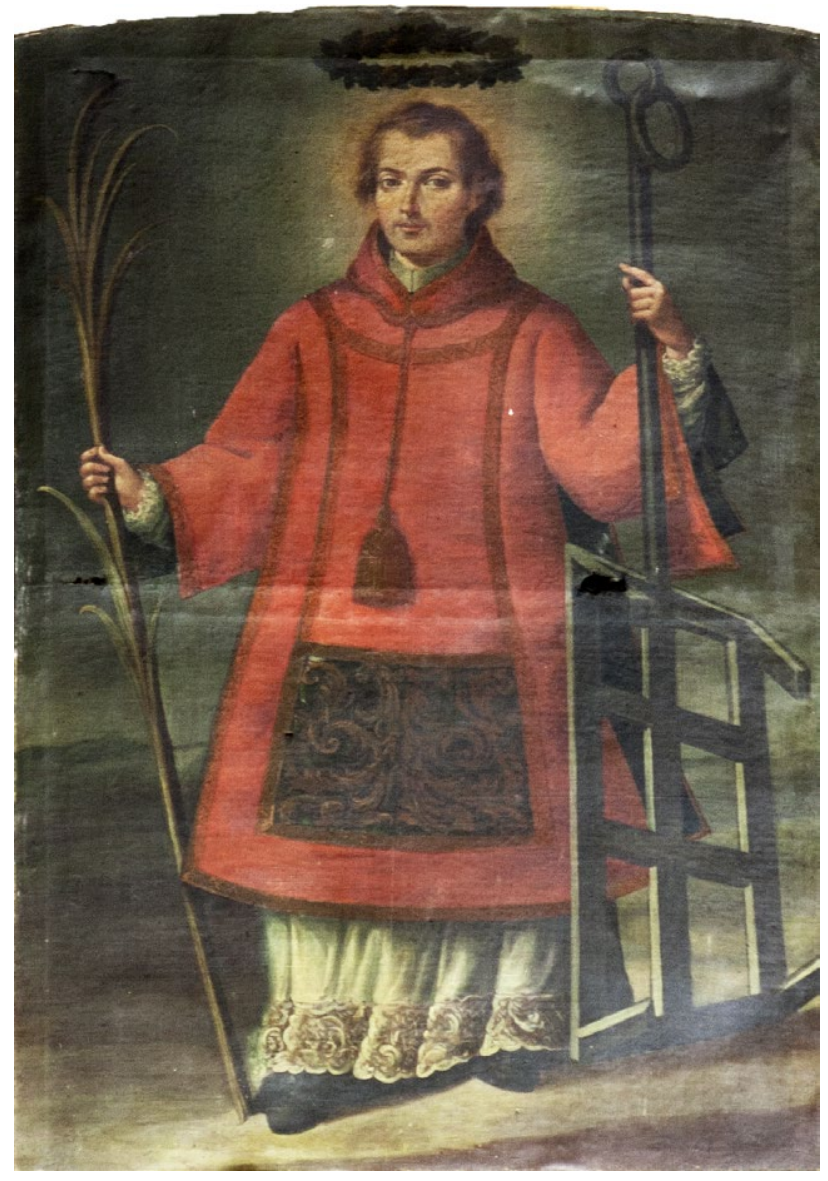

1. Vicente Alanís (atribución), San Lorenzo Mártir, c. 1770, óleo sobre lienzo, iglesia de San Juan de la Palma, nave del Evangelio, Sevilla (fotografía: Pedro M. Martínez Lara)

este en su extremo bajo con un bordado floral sobre fondo oscuro. El cuello a juego que complementa la dalmática está cerrado con un cordón que sostiene una enorme borla dorada situada justo en el centro de todo el cuadro. En la mano izquierda San Lorenzo sostiene por el asa el instrumento de 


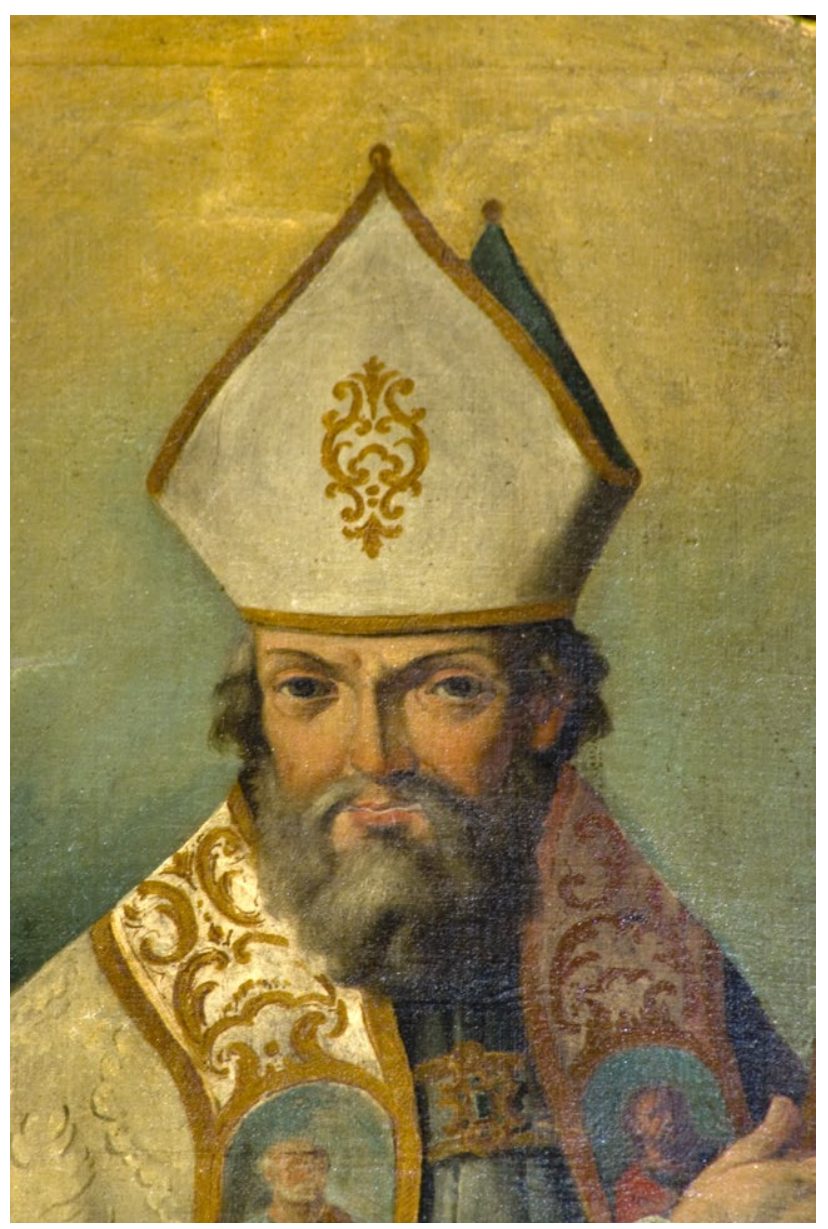

2. Vicente Alanís, San Isidoro, c. 1767, óleo sobre lienzo, parroquia de San Isidoro, presbiterio, Sevilla (fotografía: Pedro M. Martínez Lara)

su martirio: una parrilla de diseño reticular y cuatro soportes virados hacia dentro. En la derecha el símbolo de su glorificación: una larga palma que apoya en el suelo. El rostro es, al igual que las delicadas manos, de tono blanquecino, pero resulta bastante augusto por el contraste de los grandes ojos -que miran al espectador-, con la nariz, el fino bigote y la media sonrisa de los labios, que tienden a mostrar una particular idea de seguridad y determinación. Las cejas, levemente fruncidas, y el poblado cabello trigueño y ondulado, rematan una cabeza que resplandece como se cuenta en el martirologio romano ocurrió en los momentos postreros del tormento. Por encima de ella sobrevuela una corona de laurel que hace referencia al origen del nombre Laurentius «coronado de laurel», con que fue conocido este joven diácono que auxiliaba al papa San Sixto II en compañía de otros ayudantes como Januarius, Vincentius, Magnus, Stephanus, FelicísimoyAgapito, todos perseguidos y ejecutados por orden del emperador Valeriano en agosto de $258 \mathrm{~d}$. C.

En vez de enmarcar la figura en un paisaje con ruinas o vestigios romanos como optaron por hacer Zurbarán y Arango, Alanís dispone una visión casi neutra, de tono verdoso, en la que se confunde el cielo con un horizonte terroso en el que tan solo se aboceta una línea montañosa. Esta solución encuentra concordancia con la empleada en las tres composiciones de hermanos santos -San Isidoro [2], San Leandro y Santa Florentina-, del presbiterio de la parroquia sevillana de San Isidoro, conjunto que Alanís completó tras la muerte de Pedro Tortolero en 1767 (Ceán, 1800: t. V, 69). Parece como si Alanís hubiera recurrido a una misma estructura compositiva y la hubiese adaptado a cada caso en función de los rasgos y atributos iconográficos propios. Además de por ello, otro factor en el que sostengo mi atribución es la semejanza entre los rostros de los santos de aquella iglesia con el de este San Lorenzo de San Juan de la Palma. Lo mismo ocurre con los del rey purgante de la pintura de ánimas de la parroquia de la Magdalena (c. 1769) o con el de San Francisco de Paula del convento de Madre de Dios de Sevilla.

Esta pintura de San Lorenzo de Alanís está ligada a la de ánimas benditas del Purgatorio [3] realizada por su primo Francisco Miguel Jiménez de Alanís (Sevilla, 17171793), miembro de la Hermandad Sacramental de San Juan de la Palma (vid. Banda, 1995, Roda, 1996: 146 y Cabezas, 2011a: 31). Ambas están encuadradas en un retablo neoclásico de principios del siglo XIX, pero fueron realizadas probablemente al final de la década de los sesenta o a principios de los setenta del Setecientos. En el caso de Alanís, por su semejanza con las pinturas señaladas, todas de esa cronología. En el de Jiménez, por el hecho de que no ejecutó encargos tras 1775, año en que se integró en la Real Escuela de las Tres Nobles Artes de Sevilla en 1775 como teniente de pintura de Juan Espinal (Sevilla, 17141783). Esto encuadraría ambas obras entre 1767 (muerte de Tortolero) y 1775 (curso inaugural de la citada escuela de dibujo). Si es correcta esta cronología el retablo que ocuparon en origen respondería al diseño rococó con decoración a base de rocallas del momento en que la estética de Ca- 
3. Francisco Miguel Jiménez, Ánimas benditas del Purgatorio, c. 1770, óleo sobre lienzo, iglesia de San Juan de la Palma, nave del Evangelio, Sevilla (fotografía: Pedro M. Martínez Lara)

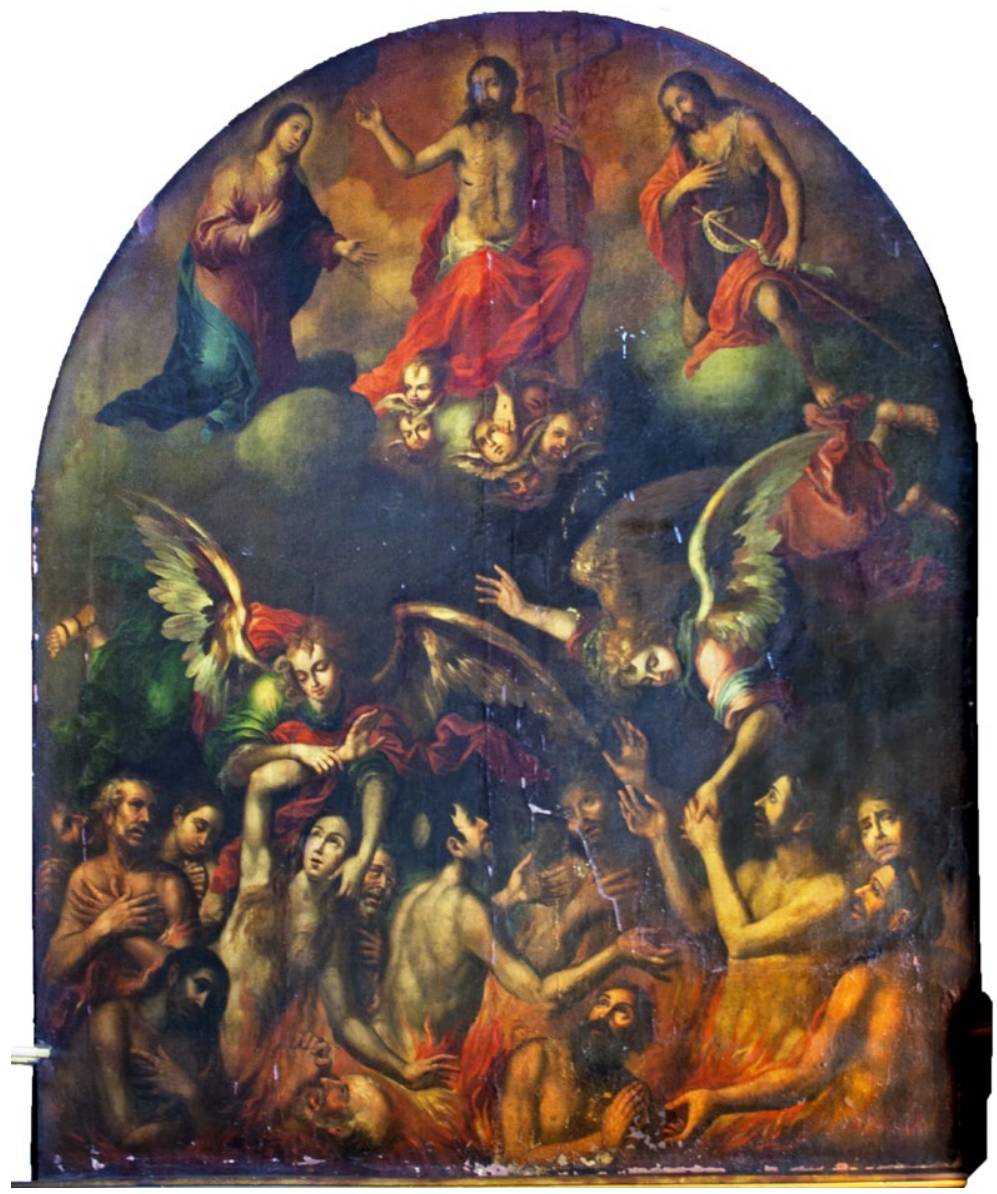

yetano de Acosta (Lisboa, 1709-Sevilla, 1778), encontraba en Sevilla más predicamento. Seguramente por eso, una vez hubo cambiado el gusto y se hizo imperativo la aplicación de la normativa regia relacionada con los retablos, se sustituiría aquel por esta sencilla máquina de reminiscencia clasicista griega (quizá su autor pudiera haber sido el retablista Manuel Barrera y Carmona. Vid. Recio, 2009: 368373). También la relación entre ambas pinturas es causada por su funcionamiento litúrgico dentro del templo. Sabido es que todas las corporaciones sacramentales rendían culto a las ánimas benditas del Purgatorio durante el mes de noviembre con objeto de alcanzar su salvación y descanso eterno. En ese sentido la devoción a San Lorenzo jugaba un papel fundamental ya que, quizá practicando una piadosa tradición de la que habla Moncada (1692: 152), el mártir tenía el privilegio de liberar cada viernes el alma de un pur- gante por haber muerto ese día. De esa manera, el disponer encima de la pintura de ánimas de Jiménez el San Lorenzo de Alanís significaba que los purgantes contaban con el amparo y protección de un santo que había sido martirizado a partir de las llamas y que se presentaba ante ellos como prueba de que las penalidades de la Tierra obtenían la gloria en el Cielo gracias a la misericordia de Dios. Respondiendo a esas cuestiones religiosas -en medio de los procesos de la devotio moderna en un momento controvertido como fue el del final del Barroco-, intentaron responder artistas como Jiménez y Alanís, pintores formados según las tradicionales prácticas de las estructuras gremiales - de las que formaron parte institucional importante (Amores, 2013)-, pero que fueron posteriormente partícipes de los intentos académicos que se acometieron en la Sevilla de los años finales del siglo XVIII. 


\section{Bibliografía}

AMORES MARTÍNEZ, Francisco (2013), «El gremio de pintores y su hermandad en la Sevilla del siglo XVIIl», Archivo Hispalense, n. ${ }^{\circ}$ 291-293, pp. 387-397.

BANDA Y VARGAS, Antonio de la (1995), «Semblanza del pintor sevillano Francisco Miguel Ximénez en el segundo centenario de su óbito», Boletín de Bellas Artes, XXIII, pp. 13-26.

CABEZAS GARCíA, Álvaro (2011a), Vicente Alanís (1730-1807), Diputación de Sevilla, Sevilla.

- (2011b), «Las pinturas de Vicente Alanís en la iglesia conventual de San Jacinto de Sevilla», Atrio, n. 17, pp. 103-118.

- (2015), Teoría del gusto y práctica de la pintura en Sevilla (1749-1835), Ayuntamiento de Sevilla, Sevilla.

CEÁN-BERMÚDEZ, Juan Agustín (1800), Diccionario histórico de los más ilustres profesores de las Bellas Artes en España, Imprenta de la viuda de lbarra, Madrid.

MONCADA, Pedro de (1692), Declamación cathólica por las benditas almas del purgatorio, regulada por la doctrina de los Concilios y Padres de la más profunda Theología, Juan García Infanzón, Madrid.

RECIO, Álvaro (2009), «El brillante final del Barroco: el retablo rococó», en HALCÓN, Fátima, HERRERA, Francisco y RECIO, Álvaro, El retablo sevillano. Desde sus orígenes a la actualidad, Diputación de Sevilla, Fundación Real Maestranza de Caballería de Sevilla, Fundación Cajasol, Sevilla.

RODA PEÑA, José (1996), Hermandades sacramentales de Sevilla, Guadalquivir Ediciones, Sevilla.

VALDIVIESO, Enrique (1986 [2002]), Historia de la pintura sevillana: siglos XIII al XX, Guadalquivir Ediciones, Sevilla. 